\title{
Creating transformative spaces for dialogue and action: reflecting on the experience of the Southern Africa Food Lab
}

\author{
$\underline{\text { Scott Drimie }}^{1,2}, \underline{\text { Ralph Hamann }}^{3}, \underline{\text { Annie P. Manderson }}^{2}$ and Norah Mlondobozi $^{2}$
}

\begin{abstract}
Addressing food insecurity in South Africa requires innovative responses that fundamentally reconsider its causes, particularly because challenges facing the food system cut across issues, sectors, and scales. We discuss our experience in the Southern Africa Food Lab, a transformative space for diverse stakeholders from across the food system to engage in dialogue, paying particular attention to the relationship between dialogue and action. We argue that dialogue gives rise to action not only because it generates new ideas but because it creates commitments and relationships for new action. A particularly important aspect of such dialogue is to proactively address power imbalances and to give voice to the marginalized in the system. Such efforts, when implemented vigorously, likely result in a new set of challenges, but such resistance is a signal that indeed we are having at least some success at addressing deepseated, structural dimensions of systems transformation.
\end{abstract}

Key Words: change; dialogue; experimental action; food systems; power imbalances; social-ecological systems; Theory U; transformative spaces

\section{INTRODUCTION}

The persistence of hunger and malnutrition in southern Africa relates to a range of complex and interrelated issues, spanning environmental, health, economic, social-political, and management domains. Ensuring that a growing population has access to a healthy, affordable, and environmentally sustainable diet will undoubtedly remain one of the greatest challenges facing the region. Reducing food insecurity requires innovative responses that fundamentally reconsider its causes, particularly as challenges facing the food system cut across issues, sectors, and scales (Bitzer et al. 2015). To date, initiatives have been fragmented, piecemeal, and difficult to scale (Pereira and Drimie 2016). The Southern Africa Food Lab (henceforth, Food Lab) seeks to respond to the recognition that "transformative spaces" are vital elements of more inclusionary and systemic responses to wicked problems (Westley et al. 2011, Moore et al. 2014; see also https://steps-centre.org/blog/coming-terms-messiness-transformation$\underline{\mathrm{lab} /})$.

The Food Lab is a multistakeholder initiative that seeks to foster long-term food security in the region. It brings together diverse, influential actors in the regional food system to respond to systemic challenges in creative ways and to inspire change in how we think about and act on complex social problems in the food system. The Food Lab facilitates dialogue between these actors to bring about collaborative learning and to foster innovation and experimental action toward a just and sustainable food system (http://www.southernafricafoodlab.org). Different actors in the food system have widely different perspectives and interests, and challenging structural issues such as power differentials among them remain largely unexamined (Pereira and Drimie 2016). These challenges make rational discourse among actors from different disciplines, sectors, and levels difficult, and prevent them from working together effectively to find innovative ways to respond to food security challenges. A key argument of the Food Lab has been that a lack of engagement between civil society, government, and the private sector has exacerbated a fragmented food system that is vulnerable to current and emergent risks. These risks can be mitigated by increasing engagement among these sectors and by creating an effective platform for authentic communication and innovation.

In essence, the Food Lab works to establish transformative spaces to support diverse actors in the food system to shift it in fundamental ways. These are spaces in which diverse actors can converge and "freely think without the weight of a disciplinary history or institutional commitments to a given approach that may constrain dialogue, co-create and prepare innovative ideas and interventions" (Pereira et al. 2015:6035). Social innovations are based on new ideas that have emerged along with the new relationships and commitments that lead to change in the system. Social innovation is a "process of learning and knowledge creation through which new problems are defined and new knowledge is developed to solve them" (Lam 2005:124).

We discuss our experience in the Food Lab and in particular the facilitation of a safe space for diverse stakeholders from across the southern African food system to interact in three phases or movements of Scharmer's (2009) Theory U: (1) "sensing" involves participants engaging with the system and each other's perspectives of it; (2) "presencing" involves reflecting more deeply about their role and possible inspiration for change; and (3) "realizing" consists of participants engaging in experimental action to pilot innovations. We argue that dialogue is a prerequisite for effective and innovative action. We emphasize the need to proactively address power imbalances in all three phases. A new set of challenges emerges when moving from dialogue to action, which we reflect on and use to refine our approach. We argue that moving into action requires continual reflection through repeating the three phases to refine what emerges. We argue that there are signs that we are having some success at finding real solutions through social innovation than merely facilitating conversations about the challenges.

\section{TRANSFORMATIVE SPACES}

The southern African food system is unsustainable. Current trends are leading to adverse social and environmental impacts such as poor health outcomes and global environmental change

${ }^{1}$ Centre for Complex Systems in Transition, Stellenbosch University, ${ }^{2}$ Southern Africa Food Lab, Stellenbosch University, ${ }^{3}$ Graduate School of Business, University of Cape Town 
(Pereira and Drimie 2016), which in turn exacerbate the negative trends through diverse feedback loops. This food system is a social-ecological system (SES) involving the complex interactions between human and biophysical components (Ericksen 2008, Cumming 2011, Sommerville et al. 2014, Tendall et al. 2015). Transforming the SES toward more just and sustainable outcomes requires alternative human-environment interactions, based on shifts in values, beliefs, and behaviors that emphasize not just productivity, but also fairness and sustainability (Olsson et al. 2014, Rockström et al. 2017).

Olsson et al. (2004) have described transformation as a process with distinct phases: (1) preparing for change, (2) navigating the transition, and (3) building resilience of the new trajectory of development (Olsson et al. 2004). Within these broad phases, there are likely to be a variety of subprocesses and within all of these there will be a need to address power imbalances between different groups (Moore et al. 2014). Transformative change will only be sustainable if it creates more just circumstances. This implies that there is a danger of reinforcing the power of dominant actors while marginalizing others if power and voice are not explicitly recognized throughout the process. Marginalized groups must be involved in stimulating transformations throughout the process of preparing, navigating the transition, and building the resilience of the new trajectory (Moore et al. 2014). Neutralizing or depoliticizing transformation processes is not possible or desirable given that any durable transformation will require altering the dominant structures of power and embedding the newly reconfigured social-ecological elements and feedbacks within institutions so that the new trajectory gains traction.

Transformative spaces may lead to social innovation if they take a systemic approach, particularly in the face of complex socialecological challenges such as the southern African food system. This focuses not just on finding solutions to problems, but also on disrupting the underlying institutional patterns that contribute to those problems. The deepest social innovations "profoundly change the basic routines, resource and authority flows, or beliefs of the social system in which the innovation occurs" (Westley and Antadze 2010:2). Such social innovations should foster new social relationships or collaborations that are built into the entire process of preparing for transformation and navigating the transition, to build resilience to sustain the new direction (Murray et al. 2010). In our view, social innovations emerge from new ideas supported by new relationships and new commitments emerging from within transformative spaces that lead to action in the system.

Social innovation labs are purposeful initiatives that seek to foster new social relationships or collaborations (Murray et al. 2010) in addressing complex social-ecological problems. They bring together diverse actors within a system, often over an extended period, to explore and experiment with the system dimensions of a given problem domain (Westley et al. 2015). Social innovation labs are intentionally trans-sectorial and transdisciplinary (Hassan 2014), drawing on diverse traditions, from social movements to action research to organizational development to design thinking (Westley et al. 2015).

Social innovation labs provide transformative spaces if they have three core characteristics: they must be social (cooperative), experimental (iterative), and systemic (addressing root causes; Hassan 2014). They should be social by bringing diverse actors together to work as a team to act collectively. They should be experimental in being on-going and sustained with the team working in an iterative manner through the process of preparation, navigation, and building resilience. They should be systemic allowing the emerging ideas and initiatives to move beyond dealing with a part or symptom of the challenge to addressing root causes of why things are not working. In this regard, transformative spaces should have longer timeframes and embrace greater uncertainty than most project-based approaches.

There is a growing body of experience feeding the design of and motivation for social innovation labs as transformative spaces (Hassan 2014, Westley et al. 2015). There is also emerging research on how dialogue between actors can contribute to the kind of institutional change required for deep social innovation (Mair and Hehenberger 2014). Olsson et al. (2008) believed we still lack a thorough understanding of how dialogue enables agency for transformative change, especially in the context of complex SES.

We see dialogue as an emergent and generative communicative interaction between participants. It goes well beyond an exchange of information to include the building of relationships that are both a means to address the challenge in question, as well as an end in themselves. In other words, dialogue is inherently relational. Although dialogical interaction can emerge spontaneously, it also deepens over time and benefits from conducive settings. Such interactions build on the participants' aspiration to listen more deeply, understand more fully, and build a collective point of view. When the diversity of actors and opinions present moments of conflict and tension, dialogue allows the conversation to be mediated back to a renewed sense of connection. The conditions for dialogue include participants committing to suspending judgment and to open their capacity to engage as listeners. Greater inquiry into others' viewpoints helps develop greater understanding of others and creates an opportunity to adopt new ways of thinking. When assumptions are explored, participants can challenge their own ideas and recognize bias and patterns of thought that influence, and possibly inhibit, engagement.

Transformative dialogue can be seen as any form of conversation or exchange that succeeds in transforming a relationship between different actors, particularly those committed to otherwise separate and sometimes antagonistic objectives, to one in which a shared vision is envisaged and acted upon (Gergen et al. 2001). In this way, dialogue has the potential to enable actors to move from the conversation to a commitment to the ideas and relationships that may have emerged. In transformational change, when it becomes necessary to redefine or reinvent a system fundamentally, triple-loop learning is necessary, which means that more fundamental reflection on purposes is required to create new ways of doing things (Waddell 2011).

A particularly pressing question raised by Olsson et al. (2008), for both practice and theory, surrounds the relationship between dialogue and action. How does dialogue lead to action or changes in action? Building on the ideas presented above, this question has been prominent in our nine-year experience in establishing and facilitating the Food Lab. Throughout, we have been sensitive to concerns that the Food Lab may be "just another talk-shop," but at the same time we held fast to the transformative potential 
of dialogue in addressing the habitual and fragmented patterns of action perpetuating the fundamentally unjust and unsustainable regional food system. The link between dialogue and action is an important aspect of the theory of change that guided the Food Lab's efforts.

\section{THE FOOD LAB'S THEORY OF CHANGE}

The Food Lab has sought to facilitate transformative dialogue by means of a process design informed by Theory U (Scharmer 2009), also referred to as the U-process. Senge et al. (2004) have described this process as enabling individuals to open beyond their preconceptions and historical ways of making sense so that they can consciously participate in a larger field for change. The hypothesis of Theory $U$ is that sustainable, transformational change is a function of shifts in individual perceptions, perspectives, and intentions, combined with shifts in collective perceptions and intentions (McLachlan and Garrett 2008). When individuals and groups take action based on changed perspectives and intentions, systemic and transformational change can occur. Given the complexity of current global problems, leaders from different parts of the system need to understand and experience the issue at hand in new ways and rigorously question their own roles in the system. Dialogue lies at the core of the process designed to deepen interactions between people and their understanding about the issue at hand.

The Food Lab's theory of change pivots on the belief that transformational change in the food system can become possible by bringing together a microcosm of influential actors in that system, in a spirit of dialogue, to deepen their understanding and appreciation of aspects of the system and to generate a new and more collective understanding of the system and their role in it. In other words, the Food Lab seeks to generate triple-loop learning (McLachlan et al. 2014). New relationships and new appreciation of the range of perspectives can create new ideas with new possibilities for change that were not visible or possible before. A collective design approach, predicated on a willingness to try out new ideas and learn together, to discard what does not work, and to refine what looks promising enables new ideas to emerge that can potentially be translated into concrete action.

The U-process consists of three phases. The first phase, "sensing," involves different role players in the system coming together in an intentional process of gaining new, shared perspectives on the system. Two key aspirations for this phase are (1) suspending judgment or enabling participants to reconsider the problem at hand without prejudice and (2) redirecting attention so that participants can gain an overview of the system, as a whole, rather than previously emphasized components.

The second phase, "presencing," is meant to enable participants to go beyond an intellectual understanding of the issues and to gain an understanding of their personal role and volition in creating change in the system. It seeks to enable participants to let go of prior convictions and prejudices and to "let come" new ideas and possibilities for action, and to crystalize specific opportunities for change.

The third phase is about "realizing" change by enabling groups of committed participants to work together to experiment and iterate new approaches to addressing the problem at hand. It involves prototyping products or processes to effect the opportunities for change identified in the presencing phase, and then, if appropriate, to institutionalize the lessons learnt more widely, for instance by influencing government rules or routines, or by replicating local initiatives elsewhere. This process, as it was adapted and applied in the Food Lab, is illustrated in Figure 1.

\section{A CASE STUDY ON APPLYING THEORY U WITH SMALLHOLDER FARMERS}

We completed a detailed case study focused on our work with smallholder farmers in South Africa. Theory $U$ guided the establishment of the Food Lab in 2010 in a year-long process organized around each of the three main phases (for descriptions and analyses of this process see McLachlan et al. 2014 and Bitzer et al. 2015). Subsequent initiatives of the Food Lab again applied the U-process design, in effect giving rise to iterative cycles of going through the "U," in which the outcomes of one cycle inspired and informed subsequent cycles (as depicted by the green and dashed arrow in Figure 1). Hence, in 2010, one of the key outcomes of our process was the shared recognition that more attention must be given to the role of marginalized smallholder farmers in the South African food system. This was not an obvious realization, given that some economists argued that the overarching priority in the food system is enhanced productivity and hence more large-scale and industrialized farming practices. The Food Lab's early work convinced a cross-section of participants of the importance of supporting smallholder farmers to ensure the food security of this marginalized group and their communities, but also to make local food systems more diverse and resilient. This is also in the context of the historical legacy of land dispossession and concentrated poverty in rural areas bequeathed by the Apartheid "homeland" policies.

Although smallholders figure prominently in political rhetoric and policy documents, there has been little clarity about how to support them in practice. Embracing this question with a range of partners including farmers' associations, researchers, government policymakers, and retailers, the Food Lab designed and implemented a wide ranging program consisting of research, learning journeys, and social innovation labs to actively shift the impasse. We focus on our work with smallholder farmers and the various activities also depicted in Figure 1 to describe how our theory of change was operationalized and to analyze what we learnt about the relationship between dialogue and action. Other initiatives of the Food Lab, such as the facilitation of a national transformative scenarios process, are described elsewhere (Freeth and Drimie 2016).

\section{WORKING THROUGH THE "U": WORKING WITH SMALLHOLDER FARMERS}

\section{Sensing the system}

Sensing is described as the phase in which we transform preconceived perceptions through actively exploring the system from different vantage points (Senge et al. 2004). During 2013, we organized three learning journeys for participants to explore the smallholder farmer system together; the yellow bus in Figure 1 represents these. Learning journeys are a way of exposing a group of people, who are united in their interest in a particular issue, but diverse in their positions and perspectives on that issue, to the current realities, experiences, and stories of people most directly affected by that issue. This exposure is an entry point into 
Fig. 1. The "U" process as adapted from Scharmer (2009) and applied in the Food Lab.

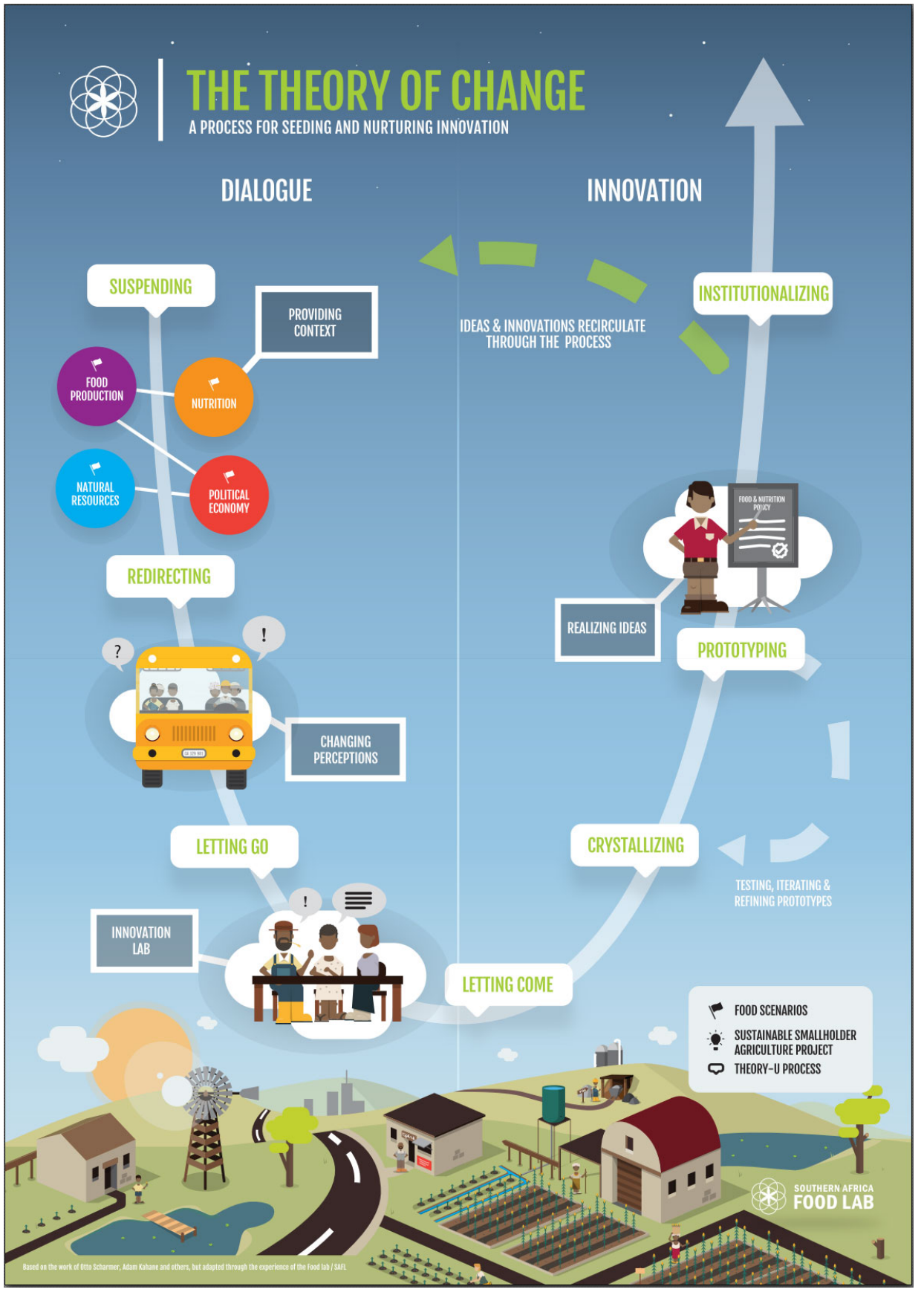

a deeper understanding of these realities and into a deeper engagement with one another about how to address these realities. Learning journeys enable both the "suspending" and "redirecting" ambitions of the sensing phase. They are important tools in developing the "collective leadership capacity [that draws] together all key stakeholders and involve[s] them in a process that begins with uncovering common intention and ends with collectively creating profound innovation on the scale of the whole system" (Scharmer 2010:2).
In the first learning journey, 18 participants were carefully selected from the private sector, civil society, government, and academia to look at the issue of market access for smallholder farmers during a 3-day facilitated process in rural parts of KwaZulu-Natal province. The themes of the various learning journeys emerged from broader consultation and research feeding into this process. Smallholder farmers and farmer support organizations were asked to host many of the interactions and experiences that occurred through the process. Participants were invited if they 
were working on this particular issue or if they played a pertinent leadership role in their sector. Selection included criteria around ensuring representation across sectors, influence, and experience in the system, as well as attention to balance between people of different roles, gender, and race.

Participants left both desk and meeting room to explore and experience for themselves, first-hand, the many, various dimensions of the complex realities they were trying to understand and influence. This process required all the participants to think about their established views, to consider why others might differ in their opinions, and to try to see the issue from others' perspectives. The participants were asked to engage with a series of questions such as: What is becoming clearer to me about the system of smallholder farming? How does this impact on the way I think about my work? What is my role and what do I have energy to do with what I am seeing here? Discussions around these questions led to several ideas on possible areas in which individuals or organizations could jointly get involved.

The second three-day rural learning journey took a different group of participants to the northern parts of Limpopo province to investigate the issue of farmer support, which had been identified in both the research supporting the process and in the previous learning journey as a pertinent issue. In this instance, participants were also selected based on sector representation, role, gender, and race. In both learning journeys the facilitation team ensured that that the voices of various smallholders and their associations were heard clearly. The Limpopo learning journey culminated in a series of conversations around the question: What ideas or actions can I initiate now?

The third learning journey focused on an urban setting. It looked specifically at commercial supply chains through the eyes of smallholder farmers. This reverse learning journey was innovative in that the hosts of the previous experiences, i.e., the smallholder farmers who had hosted the rural learning journeys, had the opportunity to participate in their own learning journey.

The learning journeys had an important impact on a number of people, both in terms of the exposure to the lived realities on the ground and also regarding the power of the process to bring people together to shake up assumptions and open people up to other perspectives, which in some cases included some quite disturbing realizations about how broken the system was. Based on experiences and discussions during one of the learning journeys, one participant noted:

Smallholder farmers are totally misunderstood; so the strategies and policies designed to help them are misdirected.

Another reflected:

Sometimes extension officers are paternalistic in their approach, and don't consider the farmers' ideas and aspirations. Even though there's a lot of talk [in government] about putting people first, the extension officers don't always listen to the farmers... When [farmers] apply for assistance, it can take a long time to come. Farming is risky, and they need disaster relief - an ambulance for farming.
Extension officers, hosting some of the sessions, countered this observation, referring to the limitations placed on them by bureaucracy and politics.

The learning journeys demonstrated the importance of skilled facilitation to hold the tensions and heated moments as groups went on a physical and relational journey together. Senior officials and executives from both the public and private sector had to, for instance, put aside their authority and take time to listen to farmers and activists, many of whom had views deeply critical of business and the state. Creating opportunities for conversation without fear of angry responses was critical. Some of the qualities demonstrated by the facilitators running the dialogue included strong listening skills, personal awareness and authenticity, asking good questions, and a holistic or systems approach to ensure connections and interrelationships were identified (Bojer et al. 2008). Facilitators were required to design an appropriate process, to mirror to participants what was going on, and to help the group become more aware. Effective questions in particular were needed to link participants with what they cared deeply about and to make visible their interdependence in finding the answers.

The learning journeys enabled participants to shift their own individual perceptions and understanding, to see the system through the eyes of others, and to develop a shared, collective understanding of what they were seeing. They built on one another in a recursive way to ensure that issues and questions that emerged were dealt with, and that thoughts on issues requiring collective action were captured for further definition. To deepen the experience and complete this first phase of the U-process, the Food Lab organized subsequent innovation labs to consolidate participants' ideas and reflections. These drew on participants and hosts that indicated a willingness to stay engaged with the process, understanding that the intention was to allow new initiatives to emerge.

\section{Presencing the system}

The emphasis in the presencing phase of the U-process is on retreating and reflecting on roles and agency as individuals and organizations, while also considering the energy of the collective. For this, the Food Lab designed two social innovation lab events to allow participants to work both individually and collectively on the ideas that had begun to emerge from the sensing phase.

It was in this presencing phase where the participants could imagine the future in a more coherent form through letting thoughts crystallize as a set of potential innovations that could lead to changes in the smallholder agriculture system. Innovations are the new ideas that have emerged together with the new relationships and new commitments that can lead to action in the system.

The presencing process culminated in the creation of the five linked innovation streams that would be tested or prototyped in two geographically defined areas: Mopani district in Limpopo and Umkhanyakude district in KwaZulu-Natal. The five interlinked streams of work were:

- Farmers' voices: this focused on the engagement of smallholder farmers to influence and advise on the development and implementation of the ideas that emerged from the Food Lab work and the policies and support models that directly affect them; 
- Standards: this aimed to disrupt the current status quo of retail procurement by engaging more smallholder farmers in food safety, ethical, and environmental standards in a streamlined process relevant to the South African smallholder context;

- Building local economies: this involved participatory research to investigate smallholder farmers' market segmentation to better focus efforts to enhance smallholders' market access;

- Agro-ecology awareness: the aim was to raise awareness among smallholder farmers for productive and resilient agro-ecosystems and improved water stewardship by drawing on localized ways of working agro-ecologically and systems thinking; and

- Farmer support: this sought to influence and enable the national policy on extension and advisory services, and pilot the collaborative approach to providing farmer support, as defined in this policy.

\section{Realizing change}

The third phase of the U-process, i.e., realizing, involved the prototyping or testing of the innovations emerging within the innovation streams. Senge et al. (2004) emphasized that it is naïve to believe that once a vision is clear, it is just a matter of implementation. The key is about acting, while remaining open and moving between inspiration and experimentation. Prototyping is a means of taking an innovation and testing it while remaining open to further inspiration. Each of the five innovation streams outlined involved prototyping efforts, both at the local level in the pilot study areas, and at a national level when, for instance, engaging the government's extension service officials. The iterative process of "learning by doing" resulted in a new initiative focused on agro-ecological training.

In our work with smallholder farmers, they frequently highlighted the need for more and better training. The government extension service is very constrained and, advice (if any) would most often be received from the salespeople of seed and fertilizer companies. This advice was clearly biased toward particular forms of farming. Building on the agro-ecology awareness innovation, developed with smallholder farmers, it was clear that these smallholder farmers were interested in developing alternative approaches, but required more and better training. One prototyping initiative, which involved a range of different actors supported by the Food Lab, focused on supporting an existing training facility to pilot leadership training for farmers with a focus on ecological farming methods. The objective was to train smallholder farmers, who would then train their peers in their own communities. The intention was to develop more sustainable and resilient farming systems across South Africa. The innovation lay in responding to what smallholder farmers identified as key to changing their own system: combining leadership training with theoretical and practical training in agro-ecological farming systems to be politically, socially, and ecologically more resilient.

In mid-2016, the Food Lab facilitated a careful selection process that identified seven smallholder farmers from the Mopani district in Limpopo (four of whom were members of the Mopani Farmers Association) to participate in a three-month pilot leadership program for trainers in agro-ecology. The objectives of the training, designed by the training facility, $17 \mathrm{Shaft}$, were to provide a three-month theoretical and practical training in leadership, agro-ecology, and skills associated with farming practices such as building, bricklaying, and basic book keeping among others. The leadership training focused on leadership and business management skills including administration skills, career development, human resources, personal development, sales and marketing, supervisors and managers, and workplace essentials. The agro-ecology training focused on soil fertility and health development, vegetable production, composting, orchards, forestry, green manures, poultry, herbal and medicinal herbs, pastures, cattle, and field crops. A key aspect of the agro-ecology training was the fact that students worked on an agro-ecological farm every day of the training, and thus received practical training related to the concepts they were discussing in class. Artisan skills training focused on basic building skills.

Additional training workshops offered by the Food Lab at 17 Shaft during the three months were based on smallholder needs assessments from previous research in the larger smallholder support program. This research was undertaken in partnership with the Institute for Poverty, Land and Agrarian Studies (PLAAS) at the University of the Western Cape. The three extra workshops included an introduction to setting up legal structures such as cooperatives, private companies, and trusts to support farmer groups with institutional development; localg.a.p. training (entry-level GLOBALG.A.P.), because supermarkets in South Africa would buy from smallholder farmers if they complied with this entry-level standard; and, an introduction to Participatory Guarantee Systems (PGS) for farmer-to-farmer learning networks and alternative market access support.

The selection of trainees was a careful process because the Food Lab wanted to identify individuals within the Mopani district that would benefit from a skills development program and then be able to transfer their learning from the course to teach others in their community without post-training support. All seven trainers successfully graduated from the program and just five weeks later facilitated their first two-day community workshop in Mopani. On the first day of their workshop, the farmers presented themselves as agro-ecology trainers and introduced their community to the basic principles of this farming practice. On the second day, the trainers provided practical demonstrations of agro-ecological practices such as compost making, mulching, crop rotation, and frame building.

The Food Lab continued to monitor these trainers' progress through on-going interactions with the Food Lab manager based near Mopani, participant observation, and two Masters-level studies focused on wider impact, evaluating whether they were able to continue independently to transfer agro-ecology knowledge and skills to their neighboring smallholder farmers. This, after all, had been the stated intention of the farmers themselves, most strongly advocated for by the Mopani Farmers Association. Indeed, two trainers applied to register an agroecology training co-operative in Mopani, another partnered with a Food Lab project manager to support the development of a formal training facility in another part of Limpopo, and another pair formally partnered with the Bryanston Organic and Natural Market in Johannesburg to establish a PGS in Nkomo village in the Mopani district, with market linkages to Bryanston. These 
were all arguably examples of real change in the lives of the trainers and the people with whom they interacted, testimony to the power of transformative dialogue. These stories further propelled the training agency that the Food Lab had worked with to embark upon a second phase of training, this time extending the geographical reach and number of trainees. By the end of 2017, the training facility was attracting sustained funding from a range of funders and had a wide range of partnerships with farmer networks, farmer support organizations, academics, and researchers.

This training of in-community trainers was the coalescence of many years of work within the Food Lab's program. Over the course of the program, the Food Lab learned that the most sustainable development projects came from listening, amplifying, and then responding to smallholder farmer voices. This work confirmed for us that the smallholder sector is a key point of entry to bring about more sustainable food systems in South Africa, because these farmers support the most vulnerable populations through informal markets, and because they have farming operations most suitable for the development of sustainable, agro-ecological, and local food systems. It is pivotal to respond to the needs of these farmers instead of imposing inflexible and decontextualized changes to their food systems, specifically their agricultural practices, which are unlikely to endure and adapt to future system shocks.

\section{CONSIDERING THE OUTCOMES OF THIS PROCESS}

To make the point about individual transformation more explicit and to reflect on our experience in working with smallholder farmers in the Food Lab, we invited one of the smallholder farmers who participated in the training workshop, Norah Mlondobozi, to join as a coauthor. As discussed earlier, sustainable, transformational change is a function of shifts in individual perceptions, perspectives, and intentions, combined with shifts in collective perceptions and intentions (McLachlan and Garrett 2008). With Norah's full consent, we thus aim to bring her direct experience into this discussion, while we also reflect on our own experiences and lessons learnt. This has been part of the ethos of the Food Lab in making smallholder voices central to the work.

Norah is a smallholder farmer from Mopani, and the previous secretary of the Mopani Farmers Association (MFA). She attended the leadership program at 17 Shaft and found the process personally transformative. She was a participant in the Food Lab's program focused on supporting smallholder farmers from the outset, and she supported the development of each of the five innovation streams. She played a particularly prominent role as project lead in the Farmers' Voices innovation to ensure that whatever unfolded in the experimentation was deeply informed by the farmers themselves. Each of the innovations adapted to become locally relevant for participating smallholder farmers in the Mopani district of Limpopo, with all five culminating in the agro-ecology leadership program.

Norah explains how Itereleng, an NGO working in Mopani, supported the development of village, area, and district-level cooperatives with the intention of establishing the MFA as a tertiary or district-level cooperative. The MFA thus emerged out of the work driven by Itereleng with leadership situated at district and area-level driving this organization of smallholder farmers.
Farmers' main motivation to join the various village associations was to increase their access resources. To date, they have been unable to receive funding from government, but because they were able to form an organized and recognizable group, they have been able to attract some resources from NGOs.

As a direct result of the five innovation processes, and in particular the agro-ecology leadership program, Norah registered another secondary cooperative for training smallholder farmers in agroecology with a fellow farmer and training graduate from 17 Shaft. Through this and her own practice on her farm she is "encouraging our whole area to farm in this way" (N. Mlondobozi 2016 , personal communication). She argues that increasingly more people can see that this approach to farming is a viable option. Local farmers were especially receptive given the recent drought and the fact that agro-ecology is a cheaper way to farm. Soil farmed using agro-ecological principles is rich with compost and local organic material and retains water, requiring less irrigation than that which is farmed through industrial methods. Her farm now employs as many as 20 women over harvest time. She is increasingly adopting agro-ecological farming principles, which she believes improve the safety of her workers, the health of consumers, and, crucially, the health of the soil.

Norah argues that the training and the revised farming practices are addressing several of the ills of the local food system identified during the sensing phase of the U-process. She believes that agroecological methods are enhancing local control and access to affordable, quality food while improving custodianship of the land and soil, and thus building more resilient production systems. Her experience of personal change is being translated into positive change for her community because she is in the process of developing the new cooperative as an agro-ecology training and processing center. Her neighbors are also increasingly adopting elements of agro-ecology. The recent drought has clearly revealed the crisis in the current system because water became a scarce resource and solutions to water scarcity were expensive, forcing many smallholder farmers to consider alternative approaches such as agro-ecology. Norah was well placed to support them in considering these options.

For Norah, it is clear that participation in the innovation processes has helped transform her thinking and perceptions. She is explicit about the change in her approach to farming and in her view of local organizing. She also argues that others participating in the process experienced similar changes in their ways of thinking. Nevertheless, her experience also shows some of the tensions that can emerge. When Norah returned to the MFA after the training program and sought to share with other members her newfound ideas and practices, this created tensions within the association.

Norah's clear leadership in agro-ecology seemed to threaten the existing, largely male leadership. When she established the secondary training co-operative, the MFA insisted she subsume this under their umbrella. They also argued that she should be deployed to facilitate training at their direction. These old ways of doing things ran contrary to Norah's vision about living the change she had experienced at 17 Shaft and working in the ways she had discovered in the larger process. As a result, she and her partner were expelled from the MFA. Her leadership was, however, recognized by a broader organization intent on supporting change in the food system, which led to her election 
on the executive of the national Food Sovereignty Campaign, to which the MFA belongs.

\section{DISCUSSION AND CONCLUSION}

What can our experience in the Food Lab tell us about the role and function of transformative spaces in social innovation? Our experience is in line with much that has been written about transformative spaces (Pereira et al.2015) and more broadly about transformation in SES (Olsson et al. 2014). Our work has underscored the potential benefits of establishing a transformative space, in which key actors in a system have an opportunity to share impressions and perceptions without, or at least with less, concern for hierarchy, prejudice, or negative repercussions. That said, we make three interrelated contributions to our understanding of transformative spaces.

First, our analysis provides some initial arguments in response to the vital question surrounding the relationship between dialogue and action (Olsson et al. 2014) and specifically the concern that such dialogue may involve little more than "talk-shops." We have defined dialogue to focus not just on the exchange of information and knowledge, i.e., the creation of new ideas, but on the creation of new commitments for new action, as well as the development of relationships that enable such commitment and action to arise. Without such commitment arising across diverse stakeholders, new initiatives have little chance of success. In our case analysis, for instance, the training workshop for smallholder farmers relied on this shared commitment and sense of ownership among diverse role players, especially the smallholders themselves.

Our second point arises directly from the first in that the important role of dialogue, in our experience and in our context, has implications for the sequencing of system transformation processes. In particular, our analysis challenges the staged model of system transformation proposed by Olsson et al. (2004) in which experimentation commences early on in the process. Our approach, and the Theory $U$ framework underpinning it (Scharmer 2009), and our subsequent experience suggest that truly innovative experiments can only be implemented once different participants in the system have had a chance to share their perspectives on the system and reflected on their own role and position in the system. If we were to imagine short-circuiting phases one and two in the process outlined, commencing with experiments earlier on, we could not imagine helpful initiatives emerging from this. Difficult conversations involving who spoke for the farmers and racial divides held early on helped new ideas to surface and strengthened emerging relationships and commitments. Interaction between people in these phases underscored the building of trust between actors that would not normally interact, which was key for building the momentum required later.

Our third argument focuses on the role of power and voice, reflecting the critique by Moore et al. (2014). In our case analysis, even though there were many government and business initiatives ostensibly seeking to support smallholder farmers, these farmers' voices were muted in existing discussions about them. The Food Lab process thus worked to put smallholder farmers' voices in the center of all its work on this topic, as reflected also by the dedicated innovation group focused on this aspect. It was only because smallholder farmers brought their concerns and ideas to the discussion, that the five innovation streams could be identified and implemented, including the culmination of one in the agroecology leadership program.

However, we learnt that such efforts to give voice to the powerless may also give rise to resistance and possible setbacks, as actors in the system become nervous when power imbalances are explicitly identified and addressed. Such resistance may arise from unexpected quarters. So, for instance, power-related tensions arose among intended beneficiaries of the agro-ecology leadership program when some smallholders worried about a course participant becoming too dominant because of her newfound knowledge and confidence.

All in all, therefore, we have learnt that dialogue is a critical prerequisite for effective and innovative action, and that a particularly important aspect of this dialogue is to proactively address power imbalances and to give voice to the marginalized within the system. Such efforts, when implemented vigorously, likely result in a new set of challenges when moving from dialogue to action, but these are signals that indeed there is at least some success at finding solutions to address deep-seated, structural dimensions of systems transformation.

Responses to this article can be read online at: http://www.ecologyandsociety.org/issues/responses. php/10177

\section{Acknowledgments:}

An early version of this paper was presented at the Resilience Conference in Stockholm in 2017. Subsequently it went through two rounds of review. We are grateful for all comments and suggestions received during this process, which helped to shape the final paper.

\section{LITERATURE CITED}

Bitzer, V., R. Hamann, M. Hall, and E. W. Griffin-EL. 2015. The business of social and environmental innovation: frontiers in research and practice in Africa. University of Cape Town Press, Cape Town, South Africa and Springer, Berlin, Germany.

Bojer, M. M., H. Roehl, M. Knuth, and C. Magner. 2008. Mapping dialogue: essential tools for social change. Taos Institute, Chagrin Falls, Ohio, USA.

Cumming, G. S. 2011. Spatial resilience and landscape analysis. Pages 143-170 in G. S. Cumming, editor. Spatial resilience in social-ecological systems. Springer, Dordrecht, The Netherlands. http://dx.doi.org/10.1007/978-94-007-0307-0 7

Ericksen, P. 2008. Conceptualizing food systems for global environmental change research. Global Environmental Change 18 (1):234-245. http://dx.doi.org/10.1016/j.gloenvcha.2007.09.002

Freeth, R., and S. Drimie. 2016. Participatory scenario planning: from scenario 'takeholders' to scenario 'owners'. Environment: Science and Policy for Sustainable Development 58(4):32-43. http://dx.doi.org/10.1080/00139157.2016.1186441

Gergen, K., S. McNamee, and F. Barrett. 2001. Towards transformative dialogue. International Journal of Public Administration 24:697-707. http://dx.doi.org/10.1081/PAD-100104770 
Hassan, Z. 2014. 'What are social innovation laboratories?' Design Management Review 25:56-59. http://dx.doi.org/10.1111/ drev.10285

Lam, A. 2005. Organizational learning. Pages 115-147 in J. Fagerberg, D. C. Mowery, and R. R. Nelson, editors. The Oxford handbook of innovation. Oxford: Oxford University Press, Oxford, UK.

Mair, J., and L. Hehenberger. 2014. Front-stage and backstage convening: the transition from opposition to mutualistic coexistence in organizational philanthropy. Academy of Management Journal 57(4):1174-1200. http://dx.doi.org/10.5465/ amj.2012.0305

McLachlan, M., and J. Garrett. 2008. Nutrition change strategies: the new frontier. Public Health Nutrition 11(10):1063-1075. http:// dx.doi.org/10.1017/S1368980007001528

McLachlan, M., R. Hamman, V. Sayers, C. Kelly, and S. Drimie. 2014. Fostering innovation for sustainable food security: the Southern Africa Food Lab. Pages 163-181 in R. Hamann, M. Hall, E. Griffin-EL, and V. Bitzer, editors. The business of social and environmental innovation: new frontiers in Africa. University of Cape Town Press, Cape Town, South Africa. http://dx.doi. org/10.1007/978-3-319-04051-6_9

Moore, M., O. Tjornbo, E. Enfors, C. Knapp, J. Hodbod, A. Baggio, A. Norström, P. Olsson, and D. Biggs. 2014. Studying the complexity of change: toward an analytical framework for understanding deliberate social-ecological transformations. Ecology and Society 19(4):54. http://dx.doi.org/10.5751/ ES-06966-190454

Murray, R., J. Caulier-Grice, and G. Mulgan. 2010. The open book of social innovation. Young Foundation, London, UK. [online] URL: http://kwasnicki.prawo.uni.wroc.pl/pliki/Social_Innovator_020310. pdf

Olsson, P., C. Folke, and T. Hahn. 2004. Social-ecological transformation for ecosystem management: the development of adaptive co-management of a wetland landscape in southern Sweden. Ecology and Society 9(4):2. http://dx.doi.org/10.5751/ ES-00683-090402

Olsson, P., C. Folke, and T. Hughes. 2008. Navigating the transition to ecosystem-based management of the Great Barrier Reef, Australia. Proceedings of the National Academy of Sciences 105(28):9489-9494. http://dx.doi.org/10.1073/pnas.0706905105

Olsson, P., V. Galaz, and W. Boonstra. 2014. Sustainability transformations: a resilience perspective. Ecology and Society 19 (4):1. http://dx.doi.org/10.5751/ES-06799-190401

Pereira, L., and S. Drimie. 2016. Governance arrangements for the future food system: addressing complexity in South Africa. Environment: Science and Policy for Sustainable Development. http://dx.doi.org/10.1080/00139157.2016.1186438

Pereira, L., T. Karpouzoglou, S. Doshi, and N. Frantzeskaki. 2015. Organising a safe space for navigating social-ecological transformations to sustainability. International Journal of Environmental Research and Public Health 12(6):6027-6044. http://dx.doi.org/10.3390/ijerph120606027
Rockström, J., J. Williams, G. Daily, A. Noble, N. Matthews, L. Gordon, H. Wetterstrand, F. DeClerck, M. Shah, P. Steduto, C. de Fraiture, N. Hatibu, O. Unver, J. Bird, L. Sibanda, and L. Smith. 2017. Sustainable intensification of agriculture for human prosperity and global sustainability. Ambio 46(1):4-17. http://dx. doi.org/10.1007/s13280-016-0793-6

Scharmer, C. 2009. Theory U. Leading from the future as it emerges: the social technology of presencing. Berrett-Koehler, Oakland, California, USA.

Scharmer, C. 2010. The blind spot of institutional leadership: how to create deep innovation through moving from egosystem to ecosystem awareness. In World economic forum annual meeting of the new champions. 13-15 September, Tianjin, People's Republic of China. [online] URL: http://www.ottoscharmer.com/sites/ default/files/2010_DeepInnovation_Tianjin.pdf

Senge, P., C. O. Scharmer, J. Jaworski, and B. S. Flowers. 2004. Presence: human purpose and the field of the future. Society for Organizational Learning, Cambridge, Massachusetts, USA.

Sommerville, M., J. Essex, and P. Le Billon. 2014. The 'global food crisis' and the geopolitics of food security. Geopolitics 19 (2):239-265. http://dx.doi.org/10.1080/14650045.2013.811641

Tendall, D., J. Joerin, B. Kopainsky, P. Edwards, A. Shreck, Q. Le, P. Kruetli, M. Grant, and J. Six. 2015. Food system resilience: defining the concept. Global Food Security 6:17-23. http://dx.doi. org/10.1016/j.gfs.2015.08.001

Waddell, S. 2011. Global Action Networks: creating our future together. Palgrave MacMillan, New York, New York, USA.

Westley, F., and N. Antadze. 2010. Making a difference: strategies for scaling social innovation for greater impact. Innovation Journal: Public Sector Innovation Journal 15(2):2010. [online] URL: https://www.innovation.cc/scholarly-style/ westley2antadze2make difference final.pdf

Westley, F., S. Laban, C. Rose, K. McGowan, K. Robinson, O. Tjornbo, and M. Tovey. 2015. Social innovation lab guide. Rockefeller Foundation, New York, New York, USA. [online] URL: https://assets.rockefellerfoundation.org/app/ uploads/20150610111553/10 SILabGuide-FINAL-1.pdf

Westley, F., P. Olsson, C. Folke, T. Homer-Dixon, H. Vredenburg, D. Loorbach, J. Thompson, M. Nilsson, E. Lambin, J. Sendzimir, B. Banerjee, V. Galaz, and S. Van der Leeuw. 2011. Tipping towards sustainability: emerging pathways of transformation. Ambio 40(7):762-780. http://dx.doi.org/10.1007/s13280-011-0186-9 